\title{
Three-dimensional numerical simulation of pressure drop and liquid holdup for high-pressure trickle-bed reactor
}

\author{
Rodrigo J.G. Lopes, Rosa M. Quinta-Ferreira* \\ Group on Environmental, Reaction and Separation Engineering (GERSE), Department of Chemical Engineering, University of Coimbra,
} Rua Sílvio Lima, Polo II, Pinhal de Marrocos, 3030-790 Coimbra, Portugal

\section{A R T I C L E I N F O}

\section{Article history:}

Received 22 May 2008

Received in revised form 20 July 2008

Accepted 23 July 2008

\section{Keywords:}

Computational fluid dynamics

Euler-Euler

Trickle-bed reactor

Multiphase flow

Hydrodynamics

\begin{abstract}
A B S T R A C T
This study aims to investigate the hydrodynamic behaviour of a trickle-bed reactor (TBR) at high pressure (30 bar) in terms of pressure drop and liquid holdup after the development of a multiphase model by means of computational fluid dynamics (CFD) codes. Taking into account transport phenomena expressed as interphase coupling terms in the momentum transfer between the gas, liquid and solid phases, an Euler-Euler model was developed resulting from the volume averaging of the continuity and momentum equations and solved for a 3D representation of the catalytic bed.

The CFD calculations were validated with experimental data from the literature and different mesh sizes were evaluated for a grid-independent CFD solution of multiphase flow in the packed bed. During grid optimization, coarse and fine physical mesh domains were applied in the hydrodynamic prediction of trickle-bed reactor. After the grid adjustment in terms of number of cells, several spherical particle diameters were tested to study its effect on hydrodynamics and it was found that pressure drop is strongly influenced by the packing size. The Eulerian mutiphase model was then used in the computation of pressure drop and liquid holdup and over a wide range for the calculated flow regime as a function of gas and liquid flow rates, the CFD theoretical predictions were in good agreement for both hydrodynamic parameters.
\end{abstract}

(c) 2008 Elsevier B.V. All rights reserved.

\section{Introduction}

Major advances for the chemical industries will, no doubt, continue to emerge from catalysis, chemistry and systems engineering. However, maximizing the industrial benefit from these advances requires comparable advances in the design of chemical process equipment. Efficient and effective design of the industrial unities ensures the delivery of materials and energy at the right places and at the right times by manipulating underlying fluid dynamics. The existing plants also need careful analysis and reengineering for improving their effectiveness and the application of computational fluid dynamics (CFD) was expected to lead to shortened product-process development cycles, optimization of existing processes to improve energy efficiency, and the efficient design of new products and processes [1]. An emerging area in lifecycle environmental applications involves multiphase flows in advanced processes for wastewater treatment, which represents a great challenge for aquatic flora and fauna preservation. In fact,

\footnotetext{
* Corresponding author. Tel.: +351 239798723; fax: +351 239798703 .

E-mail addresses: rodrigo@eq.uc.pt (R.J.G. Lopes), rosaqf@eq.uc.pt (R.M. Quinta-Ferreira)
}

bioremediation technologies have known limitations and alternative destruction methods such as catalytic wet air oxidation have been conducted successfully on a variety of organic compounds using numerous catalysts [2].

Trickle-bed reactors (TBR) are widely used for heterogeneous catalyzed reactions between gas and liquid reactants, such as hydrotreatments, oxidation or partial oxidation and detoxification of liquid effluents. In these reactors, gas and liquid phase flow co-currently downward through a fixed bed of catalyst particles. The majority of the research studies on hydrodynamics have been performed at atmospheric pressure before 1990 [3,4] while a few number of investigations was undertaken in pressurised tricklebed reactors afterwards [5-8]. Furthermore, some studies reported in the literature on the various hydrodynamic aspects of TBR was performed developing sophisticated empirical correlations [9] and using a neural network approach recently [10]. Models for TBR simulation are extensively discriminated in the literature considering isothermal operation and using a pseudo-homogeneous approach or heterogeneous model with plug-flow for gas and liquid phase with some models accounting for liquid flow non-uniformity and maldistribution by using axial dispersion models [11].

The difficulties in modelling flow in TBR are mainly due to the complex nature of the flow domain that is formed by channels 


\begin{tabular}{|c|c|}
\hline \multicolumn{2}{|c|}{ Nomenclature } \\
\hline$C_{1 \varepsilon}, C_{2 \varepsilon}$ & $k-\varepsilon$ model parameters: $1.44,1.92$ \\
\hline & particle nominal diameter $(\mathrm{m})$ \\
\hline$E_{1}, E_{2}$ & Ergun's constants \\
\hline$\vec{F}_{i}$ & interphase momentum exchange term of $i$ th phase \\
\hline$\vec{g}$ & gravitational acceleration $\left(9.81 \mathrm{~m} / \mathrm{s}^{2}\right)$ \\
\hline G & gas mass flux $\left(\mathrm{kg} /\left(\mathrm{m}^{2} \mathrm{~s}\right)\right)$ \\
\hline$k$ & $k-\varepsilon$ model kinetic energy \\
\hline$L$ & liquid mass flux $\left(\mathrm{kg} /\left(\mathrm{m}^{2} \mathrm{~s}\right)\right)$ \\
\hline$p$ & pressure (bar) \\
\hline$\Delta p$ & total pressure drop $(\mathrm{Pa})$ \\
\hline $\operatorname{Re}_{i}$ & Reynolds number of $i$ th phase $\left[\rho_{i} u_{i} d_{\mathrm{p}} / \mu_{i}\right]$ \\
\hline$\vec{u}$ & superficial vector velocity $(\mathrm{m} / \mathrm{s})$ \\
\hline \multicolumn{2}{|c|}{ Greek symbols } \\
\hline$\alpha_{i}$ & volume fraction of $i$ th phase \\
\hline$\varepsilon$ & $k-\varepsilon$ model dissipation energy \\
\hline$\varepsilon_{\mathrm{G}}$ & gas holdup \\
\hline$\varepsilon_{\mathrm{L}}$ & liquid holdup \\
\hline$\varepsilon_{\mathrm{S}}$ & solid volume fraction \\
\hline$\mu_{i}$ & viscosity of $i$ th phase (Pa s) \\
\hline$\rho_{i}$ & density of $i$ th phase $\left(\mathrm{kg} / \mathrm{m}^{3}\right)$ \\
\hline$\sigma_{k}, \sigma_{\varepsilon}$ & $k-\varepsilon$ model parameters: $1.2,1.0$ \\
\hline$\hat{\tau}_{i}$ & shear stress tensor of $i$ th phase $(\mathrm{Pa})$ \\
\hline \multicolumn{2}{|c|}{ Subscripts } \\
\hline G & gas phase \\
\hline$i$ & $i$ th phase \\
\hline $\mathrm{L}$ & liquid phase \\
\hline S & solid phase \\
\hline
\end{tabular}

around randomly packed particles. The structure of this interstitial space inside the packed bed is mainly determined by particle size, particle shape, ratio of column diameter and particle diameter and the packing method. Although the detailed 3D porosity information can be achieved through computer simulation of random packing, for flow simulation purposes the present case study employed the generation of a 3D uniform porosity distribution. Due to the inherent complexity of multiphase flows, from a physical as well a numerical point of view, general applicable CFD codes are nonexistent and the reasons for the lack of fundamental knowledge on multiphase flows are that multiphase flow is a very complex physical phenomenon where many flow types can occur (gas-solid, gas-liquid, liquid-liquid, etc.) and within each type several possible flow regimes can exist, especially in different hydrodynamic regimes that characterize the trickle-bed reactor operation (trickle flow, spray flow, pulse and bubbly flow). Also, the complex physical laws and mathematical treatment of phenomena occurring in the presence of the two phases are still largely undeveloped and the numerical algorithms for solving the governing equations and closure laws of multiphase flows are extremely complex due to its inherent oscillatory behaviour. Despite several notable works involving 2D computational studies [12,13] on trickle-bed reactors, we still do not have enough indication on predictive performance of Euler-Euler model at the catalyst level by means of 3D computations.

Recently, CFD activities have been introduced systematically in order to investigate multiphase reactors [12-16]. Most of Eulerian simulations have been carried out using a three-phase Eulerian model in where the drag-exchange coefficients are treated using the relative permeability concept or calculated by a mathematical formulation based on Ergun equation for a bidimensional compu- tational domain. Advanced experimental studies have been also carried out based on MRI imaging studies wherein the flow features predicted at the particle and liquid-rivulet scale in the TBR can be anticipated with fidelity [17]. Being aware that the design of TBR fluid dynamics controls the distribution of materials as well as the energy within the reactor vessel, a TBR was modelled at 3D to bring up hydrodynamic studies and concomitantly the assessment of mesh quality by means of CFD codes for a three-dimensional representation of packed bed flow under high-pressure operation (30 bar).

\section{Computational flow domain}

\subsection{Mesh considerations}

For successful computations of fluid flow in trickle-bed reactor operation some grid considerations during the mesh generation must be done since its intrinsic flow through the spatially varying effective viscosity plays a dominant role in the transport of mean momentum and other parameters, if high accuracy is required. In fact, the hydrodynamic well-known parameters, such as pressure drop and liquid holdup, and the strong interaction of the mean flow in catalytic bed simulations affects the numerical results for complex flows that tend to be more susceptible to grid dependency. All meshes representing catalytic bed grid generation for the tricklebed reactor were created using the integrated solid modelling and meshing commercial program GAMBIT [18]. In this study, errors arising from the mesh style and quality were of interest and in order to isolate mesh related discretization errors, a common solution procedure based on the increase of mesh density has been selected and consistently applied to the mesh styles considered.

The dimension of the pilot plant reactor is $1 \mathrm{~m}$ in length and $5 \mathrm{~cm}$ of internal diameter. In order to study the effect of different packing size on the hydrodynamic behaviour, several catalyst diameters were used (1, 2, 3, $4 \mathrm{~mm}$ diameter) and in all cases the spheres had no points of contact in order to improve the mesh quality. For all the catalyst diameters tested, the imposed gap (3\% of diameter for 3 and $4 \mathrm{~mm}$; $2 \%$ of diameter for 1 and $2 \mathrm{~mm}$ ) was confirmed that had no effect in the overall solution for both hydrodynamic parameters remaining less that $1 \%$ for the liquid holdup and $2 \%$ for the pressure drop.

To obtain grid-independent pressure drops under different operation conditions, the number of cells was increased from $2 \times 10^{5}$ to $10^{6}$. The representative three-dimensional geometry for the tetrahedral mesh of trickle-bed reactor is shown in Fig. 1(a)-(d) illustrating four cases for the number of cells from $2 \times 10^{5}$ to $10^{6}$, respectively. The computational domain is located in the axial and radial TBR centre so that it can be assumed that inlet flow effects can be neglected throughout the simulation activities. The spatial resolution or cell size in a fine mesh is less than $d_{\mathrm{p}} / 20$. These cell sizes are in line with the expected results obtained for hydrodynamic data available in open literature so that the average of a cell is in the range $0.05-0.2 \mathrm{~mm}$ depending on the simulation and geometric conditions, for particles of 1-4 mm diameter. In the trickle-bed reactor, the cells sizes are also constrained by the need to fit in between the gaps and/or narrow spaces between particles, so they cannot be too large. This can result in the erroneous values taken for proper application of wall functions available in the commercial CFD solver FLUENT so that in case of turbulent flow it were employed standard wall functions.

At $30 \mathrm{bar}$ total operating pressure, the inflow gas $\left(G=0.1-0.7 \mathrm{~kg} /\left(\mathrm{m}^{2} \mathrm{~s}\right)\right)$ and liquid $\left(L=1-15 \mathrm{~kg} /\left(\mathrm{m}^{2} \mathrm{~s}\right)\right)$ are distributed uniformly with given superficial velocity simulating a uniform distributor at the top of trickle-bed reactor. The computational mesh of the catalytic bed was reduced in length given 

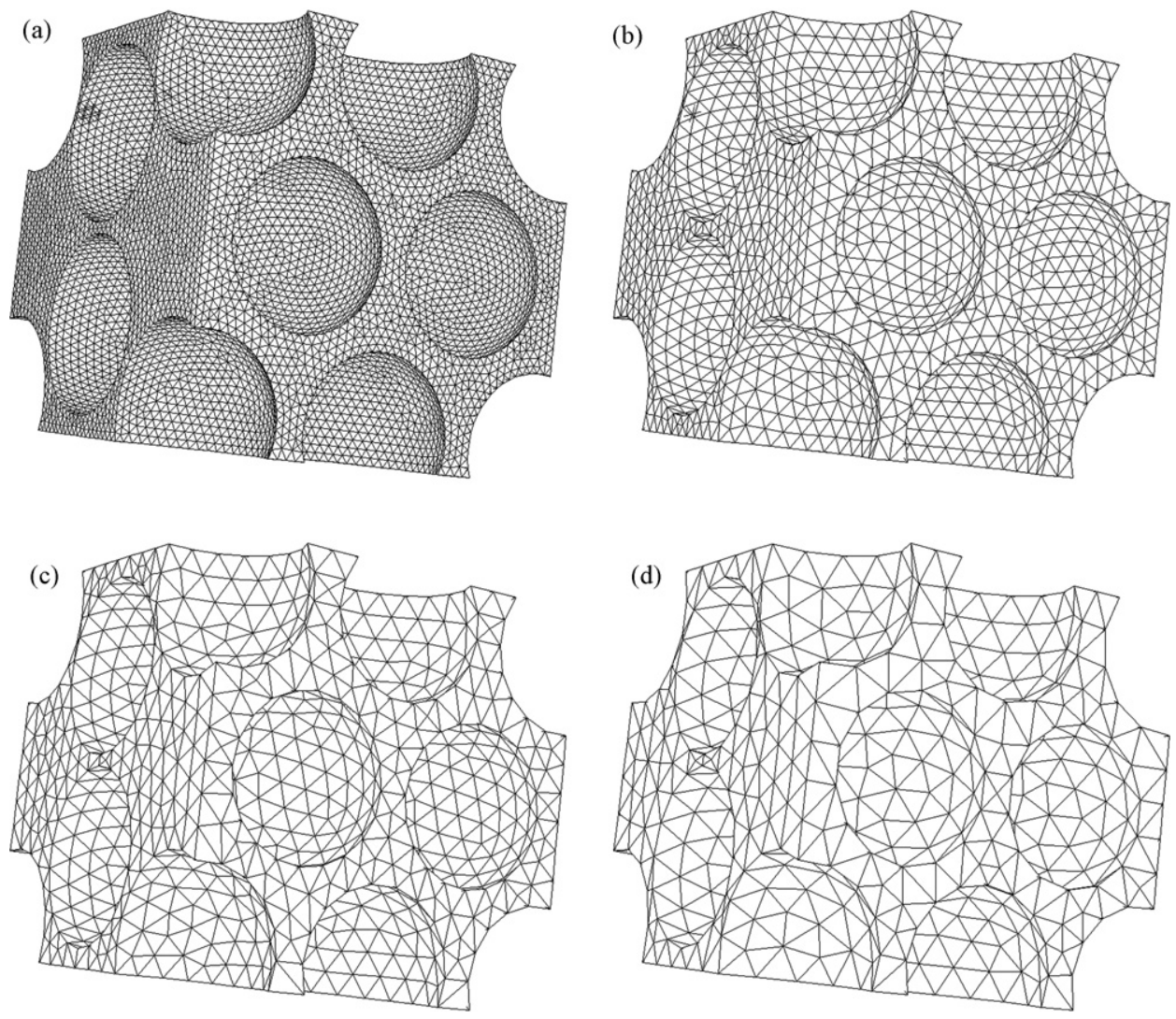

Fig. 1. Representative three-dimensional geometry and mesh for trickle-bed: (a) $10^{6}$ cells, (b) $8 \times 10^{5}$ cells, (c) $4 \times 10^{5}$ cells, and (d) $2 \times 10^{5}$ cells.

the high-memory requirements so that the reactor was filled with 10 layers in which around 200 spherical particles of $2 \mathrm{~mm}$ diameter were necessary for each axial layer. To circumvent numerical difficulties associated with the mesh generation also reported in the literature [19], the catalyst particles do not touch each other and the distance gap was fixed by $2-3 \%$ of the sphere diameter. To assess the improved total efficiency in CFD solutions offered by grid density and types, comparison and validation studies are necessary. This is especially true for multifluid systems where the flow is not predominantly oriented in one single direction arising from geometric curvature of the catalytic bed in TBR.

\subsection{Multiphase flow governing equations}

In the present work, the flow in the trickle-bed reactor was modelled using a CFD multiphasic approach incorporated in the FLUENT 6.1 [20] software that is the Euler-Euler multiphase model. In the Eulerian two-fluid approach, the different phases are treated mathematically as interpenetrating continua. The derivation of the conservation equations for mass, momentum and energy for each of the individual phases is done by ensemble averaging the local instantaneous balances for each of the phases. The current model formulation specifies that the probability of occurrence of any one phase in multiple realizations of the flow is given by the instantaneous volume fraction of that phase at that point where the total sum of all volume fractions at a point is identically unity. Fluids, gas and liquid, are treated as incompressible, and a single pressure field is shared by all phases. Turbulent flow conditions cause the fluid to behave as it has a very high momentum and thermal diffusivity, except near solid surfaces, where these transport mechanisms are reduced to laminar levels in relative short distances. Conservation equations in this section are shown in terms of rectangular Cartesian coordinates. The continuity (1) and momentum equations (2) are solved for each phase and the momentum transfer between the phases is modelled through a drag term, which is a function of the local velocity between the phases:

$$
\begin{aligned}
& \frac{\partial U_{x}}{\partial x}+\frac{\partial U_{y}}{\partial y}+\frac{\partial U_{z}}{\partial z}=0 \\
& \frac{\mathrm{D}}{\mathrm{D} t}\left(\alpha_{i} \rho_{i} \vec{U}_{i}\right)=-\alpha_{i} \nabla p+\nabla \cdot \hat{\tau}_{i}+\alpha_{i} \rho_{i} \vec{g}+\sum_{p=1}^{n} \vec{F}_{i j}\left(\vec{U}_{i j}-\vec{U}_{j i}\right)
\end{aligned}
$$

Interphase coupling terms, $\vec{F}_{i j}$, in the right side of Eq. (2) were formulated based on similar equations to those that are typically used to express the pressure drop for packed beds by means of Ergun equation. Consequently, the model of Attou and Ferschneider [21] was employed in the CFD model, which includes gas-liquid interaction forces and it was developed for the regime in which liquid flows in the form of film. The interphase coupling terms are expressed in terms of interstitial velocities and phase volume fractions for gas-liquid, gas-solid and liquid-solid momentum exchange forms:

$$
\begin{aligned}
F_{\mathrm{GL}}= & \varepsilon_{\mathrm{G}}\left(\frac{E_{1} \mu_{\mathrm{G}}\left(1-\varepsilon_{\mathrm{G}}\right)^{2}}{\varepsilon_{\mathrm{G}}^{2} d_{\mathrm{p}}^{2}}\left[\frac{\varepsilon_{\mathrm{S}}}{1-\varepsilon_{\mathrm{G}}}\right]^{2 / 3}\right. \\
& \left.+\frac{E_{2} \rho_{\mathrm{G}}\left(u_{\mathrm{G}}-u_{\mathrm{L}}\right)\left(1-\varepsilon_{\mathrm{G}}\right)}{\varepsilon_{\mathrm{G}} d_{\mathrm{p}}}\left[\frac{\varepsilon_{\mathrm{S}}}{1-\varepsilon_{\mathrm{G}}}\right]^{1 / 3}\right)
\end{aligned}
$$




$$
\begin{aligned}
F_{\mathrm{GS}}= & \varepsilon_{\mathrm{G}}\left(\frac{E_{1} \mu_{\mathrm{G}}\left(1-\varepsilon_{\mathrm{G}}\right)^{2}}{\varepsilon_{\mathrm{G}}^{2} d_{\mathrm{p}}^{2}}\left[\frac{\varepsilon_{\mathrm{S}}}{1-\varepsilon_{\mathrm{G}}}\right]^{2 / 3}\right. \\
& \left.+\frac{E_{2} \rho_{\mathrm{G}} u_{\mathrm{G}}\left(1-\varepsilon_{\mathrm{G}}\right)}{\varepsilon_{\mathrm{G}} d_{\mathrm{p}}}\left[\frac{\varepsilon_{\mathrm{S}}}{1-\varepsilon_{\mathrm{G}}}\right]^{1 / 3}\right) \\
F_{\mathrm{LS}}= & \varepsilon_{\mathrm{L}}\left(\frac{E_{1} \mu_{\mathrm{L}} \varepsilon_{\mathrm{S}}^{2}}{\varepsilon_{\mathrm{L}}^{2} d_{\mathrm{p}}^{2}}+\frac{E_{2} \rho_{\mathrm{L}} u_{\mathrm{G}} \varepsilon_{\mathrm{S}}}{\varepsilon_{\mathrm{L}} d_{\mathrm{p}}}\right)
\end{aligned}
$$

For incompressible flows, the turbulence parameters are calculated from Eqs. (6)-(8):

$$
\begin{aligned}
& \frac{\partial}{\partial t}\left(\rho_{\mathrm{L}} \alpha_{\mathrm{L}} k_{\mathrm{L}}\right)+\nabla \cdot\left(\rho_{\mathrm{L}} \alpha_{\mathrm{L}} \vec{u}_{\mathrm{L}} k_{\mathrm{L}}\right) \\
& \quad=\nabla \cdot\left(\alpha_{\mathrm{L}} \frac{\mu_{t, \mathrm{~L}}}{\sigma_{k}} \nabla k_{\mathrm{L}}\right)+\alpha_{\mathrm{L}} G_{k, \mathrm{~L}}-\alpha_{\mathrm{L}} \rho_{\mathrm{L}} \varepsilon_{\mathrm{L}}+\alpha_{\mathrm{L}} \rho_{\mathrm{L}} \Pi_{k \mathrm{~L}}
\end{aligned}
$$

$$
\begin{aligned}
& \frac{\partial}{\partial t}\left(\rho_{\mathrm{L}} \alpha_{\mathrm{L}} \varepsilon_{\mathrm{L}}\right)+\nabla \cdot\left(\rho_{\mathrm{L}} \alpha_{\mathrm{L}} \vec{u}_{\mathrm{L}} \varepsilon_{\mathrm{L}}\right) \\
& \quad=\nabla \cdot\left(\alpha_{\mathrm{LL}} \frac{\mu_{t, \mathrm{~L}}}{\sigma_{\varepsilon}} \nabla \varepsilon_{\mathrm{L}}\right)+\alpha_{\mathrm{L}} \frac{\varepsilon_{\mathrm{L}}}{k_{\mathrm{L}}} \times\left(C_{1 \varepsilon} G_{k, \mathrm{~L}}-C_{2 \varepsilon} \rho_{\mathrm{L}} \varepsilon_{\mathrm{L}}\right)+\alpha_{\mathrm{L}} \rho_{\mathrm{L}} \Pi_{\varepsilon \mathrm{L}}
\end{aligned}
$$

$$
\tau_{t}=\mu_{t}\left(\frac{\partial U_{i}}{\partial x_{j}}+\frac{\partial U_{j}}{\partial x_{i}}\right)-\frac{2}{3} \delta_{i j}\left(\rho k+\mu_{t} \frac{\partial U_{k}}{\partial x_{k}}\right)
$$

In these equations, $G_{k}$ is the generation of turbulent kinetic energy, $k$, due to the mean velocity gradients (turbulent stress) as expressed in Eq. (9):

$G_{k}=-\rho \overline{U_{i}^{\prime} U_{j}^{\prime}} \frac{\partial U_{j}}{\partial x_{i}}$

where $C_{1 \varepsilon}$ and $C_{2 \varepsilon}$ are the constants of standard $k-\varepsilon$ model whereas $\sigma_{k}$ and $\sigma_{\varepsilon}$ are the turbulent Prandtl numbers for $k$ and $\varepsilon$, respectively. $\delta_{i j}$ is Kronecker delta and $k$ subscript indicates a summation over the $x_{k}$ Cartesian coordinates.

\subsection{Numerical simulation, boundary conditions and wall functions}

The solution method was control-volume-based for multiple mesh styles including structured hexahedral, unstructured tetrahedral, and hybrid meshes. User-supplied C programs have been employed for the calculation additional multiphase interactions, grid convergence and post-processing. All transport equations were discretized to be at least second order accurate in space. A segregated implicit solver was employed to evaluate the resulting linear system of equations using the Gauss-Seidel method in conjunction with an algebraic multigrid approach to solve the linearized equations. The governing equations were solved using the SIMPLE algorithm and the momentum equations were decoupled using the full elimination algorithm in which the variables for each phase are eliminated from the momentum equations for all other phases. The pressure correction equation was obtained by summing the continuity equations for each of the phases. The equations were then solved in a segregated, iterative fashion and were advanced in time. Model equations were solved in a transient fashion with a time step of $0.001 \mathrm{~s}$ for the Eulerian simulations. At each time step, with an initial guess for the pressure field, the primary- and secondary-phase velocities were computed. These were used in the pressure correction equation and based on the discrepancy between the guessed pressure field and the computed field, the velocities, $L / G$ holdups and fluxes were suitably modified to obtain convergence in an iterative manner. The outer iteration procedure was stopped when the global mass residual had been reduced
Table 1

Parameters used in the CFD simulation

\begin{tabular}{ll}
\hline Grid & $1000 \mathrm{~mm}($ axial $) \times 50 \mathrm{~mm}$ (radial) \\
Cell size & $0.05-0.20 \mathrm{~mm}$ (tetrahedral and \\
& hexahedral) \\
Particle diameter & $1,2,3,4 \mathrm{~mm}$ (spheres) \\
Time step & $0.001 \mathrm{~s}$ (Euler-Euler) \\
Iterations & $\approx 50,000$ \\
Under-relaxation parameters & Euler-Euler: 0.4 (pressure), 0.6 \\
& (velocity) \\
Drag formulation & Attou and Ferschneider (1999) [2] \\
Turbulence model & Laminar; standard $k-\varepsilon$ model \\
Total pressure & $30 \mathrm{bar}$ \\
Temperature & $298 \mathrm{~K}$ \\
Gas flow rate & $0.1-0.7 \mathrm{~kg} /\left(\mathrm{m}^{2} \mathrm{~s}\right)$ \\
Gas density (298.15 K, 30 bar) & $35.670 \mathrm{~kg} / \mathrm{m}^{3}$ \\
Gas viscosity (298.15 K, 30 bar) & $1.845 \times 10^{-5} \mathrm{~Pa} \mathrm{~s}$ \\
Liquid flow rate & $1-15 \mathrm{~kg} /\left(\mathrm{m}^{2} \mathrm{~s}\right)$ \\
Liquid density (298 K, 30 bar) & $998.39 \mathrm{~kg} / \mathrm{m}^{3}$ \\
Liquid viscosity (298 K, 30 bar) & $8.925 \times 10^{-4} \mathrm{~Pa} \mathrm{~s}$ \\
Liquid surface tension (298 K, 30 bar) & $7.284 \times 10^{-2} \mathrm{~N} / \mathrm{m}$ \\
\hline
\end{tabular}

from its original value by five orders of magnitude and when the residual-reduction rates for both mass and momentum were sufficiently small and less than $10^{-6}$. All calculations were performed in double precision to improve accuracy. Experimentally, it is observed that trickle-bed reactors presents random directional flow fields imposing serious limitations in the convergence of tetrahedral meshes that could lead to an inefficient distribution of grid points in the final mesh. Therefore, the under-relaxation parameter for pressure was checked in the range between 0.2 and 0.6 whereas for velocity it was checked in the range $0.4-0.8$. The common parameters used in the simulation are summarized in Table 1.

In case of turbulent flow modelling, a set of customized $k-\varepsilon$ equations was used to describe the turbulence flow including terms characterizing interphase turbulent momentum derived from the instantaneous equation of the continuous phase and involves the velocity covariance. Inlet boundary conditions are assigned at the top distributor and outlet conditions at the free surface. The cell thickness $\left(y^{+}\right)$computed by the CFD solver was always below than 200. At this point, it was possible to check the near-wall mesh in the post-processing treatment. The solution independency was then established after several assays with the definition of turbulence boundary conditions available in $k-\varepsilon$ model. The boundary conditions at the walls are internally computed by FLUENT 6.1, which obviates the need for boundary condition inputs for $k$ and $\varepsilon$ supplied by inlet boundaries, specifically velocity $[15,16]$. Pressure inlet was also tested but the results seem to be well described by inlet velocity which specify more realistic boundary conditions at the inlet. It should be pointed that inlet turbulence can significantly affect the downstream flow as observed in high-pressure tricklebed reactor. In the trickle-bed simulations performed, the fidelity of the results for turbulent flows was addressed by the turbulence model being used and in order to enhance the quality of turbulent flow simulations, the mesh generation accounts for wall-bounded flow on catalyst particle, since the wall is expected to significantly affect the flow.

In order to establish grid independence of the velocity field solutions, successive refinements of each mesh style have been considered. For each refinement, grid convergence was evaluated by using a relative error measure of velocity magnitude between the coarse and fine solutions. The conditions required for grid convergent results are based on a $1 \%$ relative error criterion and the simulations accuracy has been assessed by comparisons to experimental data available in the literature [22] for the simulated velocity field. 


\section{Results and discussion}

\subsection{Mesh optimization and validation}

Validation of CFD flow field calculations has generally taken one of two forms. In the first, non-invasive velocity measurements inside the packed bed have been made and compared to velocities computed from a model of either the entire experimental bed or a representative part of it. In the second form, computed pressure drops have been compared to either measured values or established correlations for pressure drop in fixed beds, such as the Ergun equation. The present case study makes use of the last method to assess the Eulerian model so that the numerical methodology is validated against experimental data available from literature related to the hydrodynamic information for TBR operation [22]. Different hydrodynamic regimes were simulated for the trickle-bed reactor either in laminar or turbulent flow. In both cases, the local refinement and coarsening of unstructured tetrahedral meshes in the case study required local grid modifications to efficiently resolve solution features for computing unsteady three-dimensional problems that arises in TBR simulation activities. In laminar flow, the mesh aperture was optimized near the catalyst and reactor walls. The higher level of numerical diffusion usually associated with tetrahedral meshes could not always be defeated increasing the number of cells since significant numerical diffusion errors and inaccuracies in near-wall particle interpolations may persist. The resulting liquid holdup and pressure drop along the catalytic bed were evaluated as a function of cells number as well as operating conditions.

The mesh strongly affects the accuracy of the simulation as shown by Fig. 2 . It has to be chosen with enough detail to describe the multiphase flow accurately and with a degree of coarseness that enables solution within an acceptable amount of time. We determined an appropriate mesh density for CFD simulations by comparing computational results from several different mesh sizes and then an optimal mesh density was established for hydrodynamic validation in trickle-bed operation. In hydrodynamic studies no differences were observed between the flow solutions whether a completely fine mesh was used or a locally refined mesh. The mesh used for the TBR is characterized by the edge length of the tetrahedral cells, the thickness of the first layer of prismatic cells on the solids surface (sphere or channel wall), the expansion rate of the prismatic cells and the number of layers of prismatic cells. An edge length of $0.15 \mathrm{~mm}$ on a $3 \mathrm{~mm}$ diameter sphere corresponds to a number of about 3000 triangles in the surface mesh of the

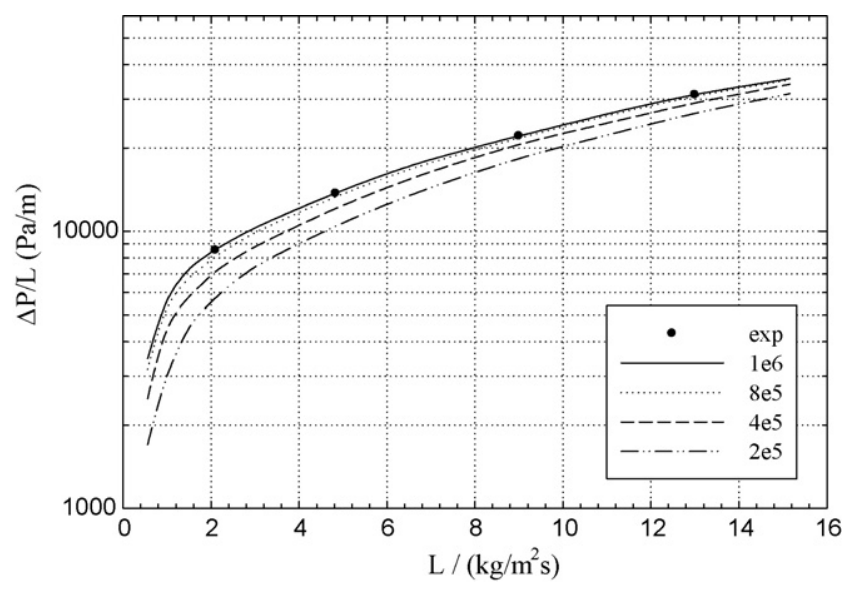

Fig. 2. Effect of numerical parameters on pressure drop vs. liquid flow rate for different cells number: $10^{6}, 8 \times 10^{5}, 4 \times 10^{5}, 2 \times 10^{5}\left(P=30\right.$ bar, $G=0.5 \mathrm{~kg} /\left(\mathrm{m}^{2} \mathrm{~s}\right), d=2 \mathrm{~mm}$; experimental data from Nemec and Levec [22]).

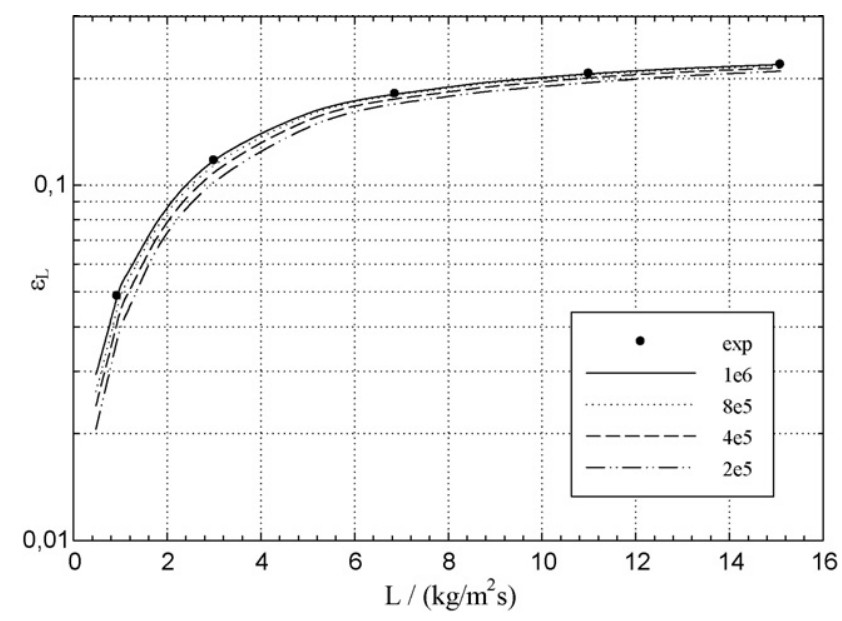

Fig. 3. Effect of numerical parameters on liquid holdup vs. liquid flow rate for different cells number: $10^{6}, 8 \times 10^{5}, 4 \times 10^{5}, 2 \times 10^{5}\left(P=30\right.$ bar, $G=0.1 \mathrm{~kg} /\left(\mathrm{m}^{2} \mathrm{~s}\right), d=2 \mathrm{~mm}$; experimental data from Nemec and Levec [22]).

sphere, whereas an edge length of $0.2 \mathrm{~mm}$ corresponds to about 1000 triangles.

In accordance with Figs. 2 and 3, for laminar flow, a total of about one million grid cells were needed when using a tetrahedral mesh edge length $0.15 \mathrm{~mm}$. In terms of number of cells, the mesh dependency addressed in pressure drop (Fig. 2) and liquid holdup (Fig. 3) computations is proportionally direct, as expected. In fact, if we increase the number of cells, the result is to enhance the grid detail accounting the void space in an appropriate manner. Numerically, this brings more iterations towards the convergence. In the current multiphase flow simulation, the grid independence of the solution was checked by varying the grid type and grid density near the walls. In Fig. 2 the resulting pressure drops across the packed bed were plotted as a function of the cells number. This figure indicates that $10^{6}$ of cells are adequate to successfully predict pressure drop as well as the liquid holdup within $10 \%$ relative error, this one demonstrated in Fig. 3. Comparing these two plots (Figs. 2 and 3), the TBR operation seems to be more sensible to pressure drop than to liquid holdup results when performing the same deviation scale in the cells number.

\subsection{Influence of packing size on hydrodynamics}

The catalytic bed was simulated with different packing made of spherical particles with diameters up to $4 \mathrm{~mm}$. Indeed, the validation method was to compare simulation results in terms of pressure drop (Fig. 4) and liquid holdup (Fig. 5) evaluating the mesh sensitivity and discriminating the numerical results against the experimental data performed with equipment analogous to the system that is being replicated [22]. Geometrically, the trustworthiness of this modus operandi led to the final corroboration of CFD codes.

When the trickle-bed reactor is simulated with different spherical particle diameters, the overall effect of particles size is related to the specific surface area of the packing material for that particular bed. For instance, if the TBR is operated with spheres of $d=1 \mathrm{~mm}$, the specific surface is higher than it is for spheres of $d=4 \mathrm{~mm}$ leading to the greater flow resistance. Therefore, as the particle size decreases, the specific surface area of the bed increases and therefore the liquid holdup (Fig. 5) also increase due to the fact that liquid phase finds it harder to flow downwards through the bed at a certain gas and liquid flow rate. 


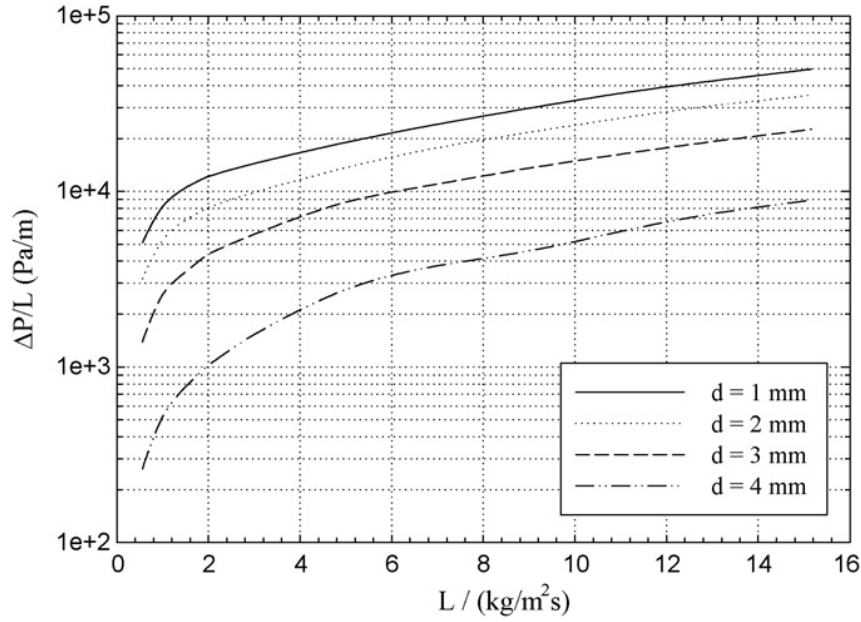

Fig. 4. Effect of packing size on pressure drop vs. liquid flow rate for different packing particles: $1-4 \mathrm{~mm}\left(P=30 \mathrm{bar}, G=0.5 \mathrm{~kg} /\left(\mathrm{m}^{2} \mathrm{~s}\right)\right)$.

According to Fig. 4, one can observe that pressure drop also increases due to the increased bed specific surface area. The effect is more pronounced when the simulation is addressed in two-phase flow due to an additional increase in pressure drop than if one compares it to single-phase flow operation. This fact is associated with the enlargement of liquid holdup, which decreases the available void space for the flow of gas through the trickle-bed reactor.

\subsection{Evaluation of pressure drop and liquid holdup predictions}

After evaluating the mesh quality and its numerical independency for the TBR modelling, Eulerian model was used to predict pressure gradient and liquid holdup in scale-up activities to evaluate the effect of liquid and gas flow rates in the hydrodynamic parameters. The well-established design of the TBR performance depends heavily in the accurate quantification of pressure drop because it affects the energy supply at the catalyst particle and it has been used to correlate the gas-liquid and solid-liquid mass transfer $[23,24]$. On the other side, the validation in terms of liquid fraction contained in the TBR column was referred with laboratory scale experiments. Therefore, whereas pressure drop is obviously connected with the dissipation power in the multiphase reactor that cannot be neglected when optimization is a

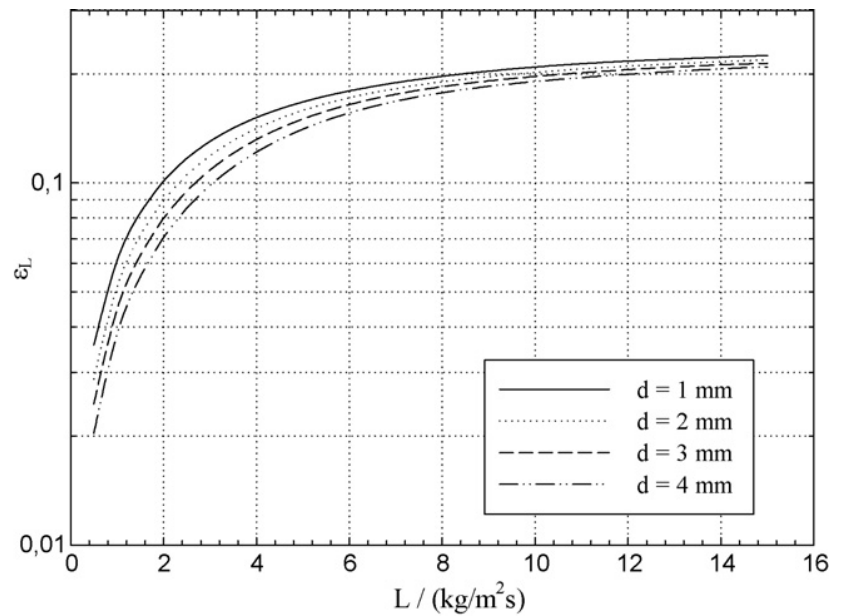

Fig. 5. Effect of packing size on liquid holdup vs. liquid flow rate for different packing particles: $1-4 \mathrm{~mm}\left(P=30\right.$ bar, $\left.G=0.1 \mathrm{~kg} /\left(\mathrm{m}^{2} \mathrm{~s}\right)\right)$.

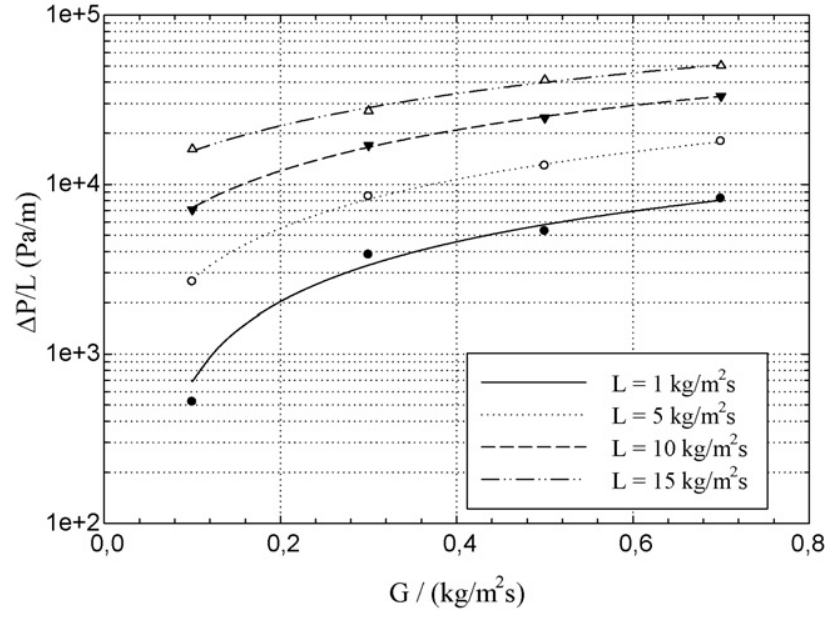

Fig. 6. Effect of liquid flow rate on pressure drop vs. gas flow rate $(P=30$ bar, $d=2 \mathrm{~mm}$; experimental data from Nemec and Levec [22]).

subject matter, liquid holdup is particularly important when assessing the trickle flow encountered at low-gas and -liquid superficial velocities.

Two-phase pressure gradient results are plotted as a function of gas flow rated varying the liquid flow rate and vice versa in Figs. 6 and 7. The variation of the internal pressure per unit-reactor length is directly proportional to any phase flow rate. In fact, at the lowest liquid flow rate $\left(1 \mathrm{~kg} /\left(\mathrm{m}^{2} \mathrm{~s}\right)\right)$ if we decrease the operating gas flow rate from 0.7 to $0.1 \mathrm{~kg} /\left(\mathrm{m}^{2} \mathrm{~s}\right)$, the total pressure drop shifts from 8210 to $520 \mathrm{~Pa} / \mathrm{m}$, whereas the same relative change at the lowest gas flow rate $\left(0.1 \mathrm{~kg} /\left(\mathrm{m}^{2} \mathrm{~s}\right)\right)$ in liquid flow rate it only produces a modification in terms of pressure drop from 4065 to $520 \mathrm{~Pa} / \mathrm{m}$. Therefore, $86 \%$ of reduction in the gas flow rate has a major effect for pressure drop (94\%) rather than with the same reduction order for the liquid flow rate (87\%). Moreover, the effect of gas flow rate on the pressure drop is enlarged at higher flow rates $\left(G=0.7 \mathrm{~kg} /\left(\mathrm{m}^{2} \mathrm{~s}\right)\right)$ so that a shift from 15 to $1 \mathrm{~kg} /\left(\mathrm{m}^{2} \mathrm{~s}\right)$ in liquid flow rate make the pressure drop move from 50,250 to $8210 \mathrm{~Pa} / \mathrm{m}$; whilst at $L=15 \mathrm{~kg} /\left(\mathrm{m}^{2} \mathrm{~s}\right)$ the pressure drop is already $16,124 \mathrm{~Pa} / \mathrm{m}$ at the highest gas flow rate $\left(G=0.7 \mathrm{~kg} /\left(\mathrm{m}^{2} \mathrm{~s}\right)\right)$. Having the knowledge that pressure gradient is related to the mechanical energy dissipation due to the two-phase flow through the fixed bed of solid

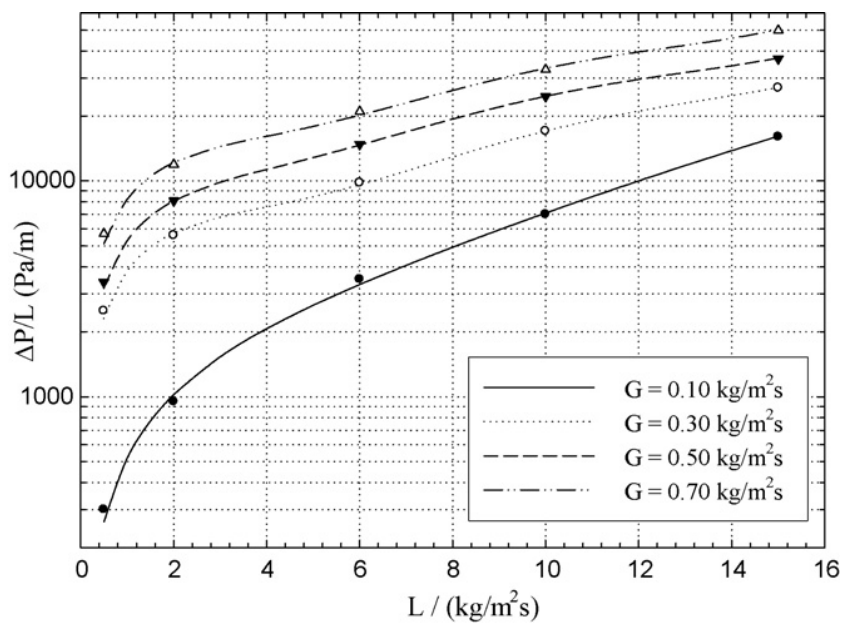

Fig. 7. Effect of gas flow rate on pressure drop vs. liquid flow rate ( $P=30 \mathrm{bar}$, $d=2 \mathrm{~mm}$; experimental data from Nemec and Levec [22]). 

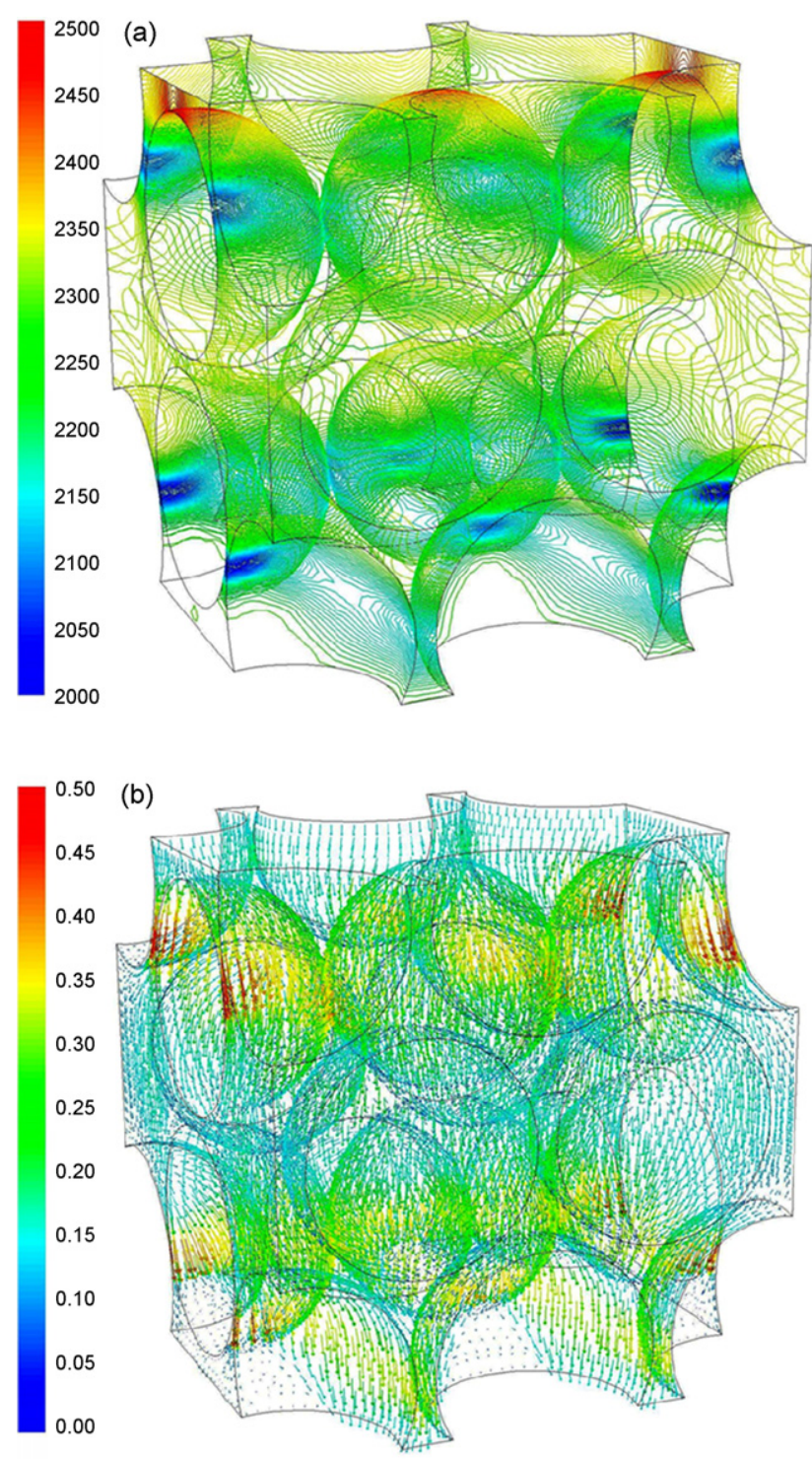

Fig. 8. (a) Isocontour of pressure (Pa) field on the catalyst surface; (b) flow pattern on the catalyst surface area showing instantaneous gas velocity vector $(\mathrm{cm} / \mathrm{s})(P=30 \mathrm{bar}$, $\left.L=5 \mathrm{~kg} /\left(\mathrm{m}^{2} \mathrm{~s}\right), G=0.7 \mathrm{~kg} /\left(\mathrm{m}^{2} \mathrm{~s}\right), d=2 \mathrm{~mm}\right)$.

catalyst particles, comparing Figs. 6 and 7 illustrate that the effect at low-gas flow rates is more meaningful for the pressure drop. As expected, the liquid flow rate has not parallel influence as shown in Fig. 7.

Fig. 8(a) shows an isocontour for the pressure field on the catalyst surface. As one can observe, the values of lower pressure were encountered in zones where the catalyst particles are closer to each other. As the flow is processed downwards, the higher pressure values were monitored at the top zone of the catalyst particle so that the fluid is compelled to navigate around the sphere and changing its flow direction. To illustrate the flow direction adjustment around catalyst packing, Fig. 8(b) also supports this fact in which the mean gas velocity is in accordance with the hydrodynamic regime simulated. Indeed, the maximum velocity attained for the gas phase is about $0.5 \mathrm{~cm} / \mathrm{s}$ which enables the trickling flow operating conditions. According to Fig. 8(b), the computed vector field shows that phase velocity is not always fully developed around the catalyst particle and the higher values is observed in the sphere equatorial zone. The asymmetric gas velocities depicted in Fig. 8(b) between two or more catalyst particles as well as the pressure contours plot-

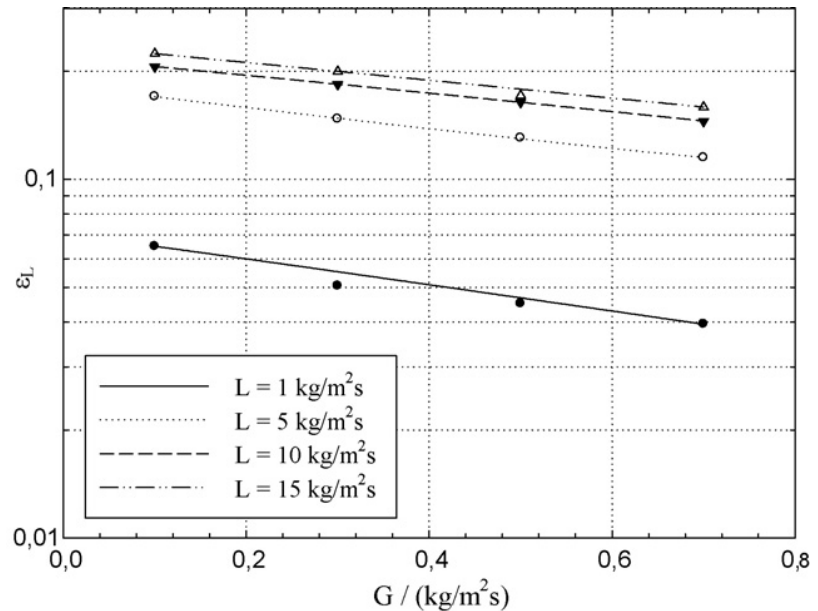

Fig. 9. Effect of liquid flow rate on liquid holdup drop vs. gas flow rate ( $P=30$ bar $d=2 \mathrm{~mm}$; experimental data from Nemec and Levec [22]).

ted in Fig. 8(a) demonstrate the existence of poor gas-liquid flow distribution in the packed bed as a consequence of rough stagnant zones.

In what concerns liquid holdup predictions, conversely to the effect advanced for the influence of the liquid flow rate in the computed global pressure drop, after the examination of Figs. 9 and 10, liquid holdup does not generate the same assertions. In fact, while the increasing of gas flow rate tends to reduce the volume of liquid contained in the bed per unit reactor volume, the opposite behaviour is observed when the liquid flow rate is charged. The influence of liquid holdup is also related to other important parameters, namely, pressure gradient, gas-liquid interfacial area, the mean residence time of the liquid phase, catalyst loading per unit volume, mass-transfer and heat-transfer coefficients. Notwithstanding, the Euler multiphase model takes into account the total liquid holdup resulting from the sum of static and dynamic liquid holdup and according to Fig. 9, we could state that the semi-log plot report this hydrodynamic parameter as a linear decreasing function of gas flow rate, as expected.

Taking into account that hydrodynamics are affected differently in each flow regime and the operating conditions that are of particular interest in the industry is the extensively used trickle

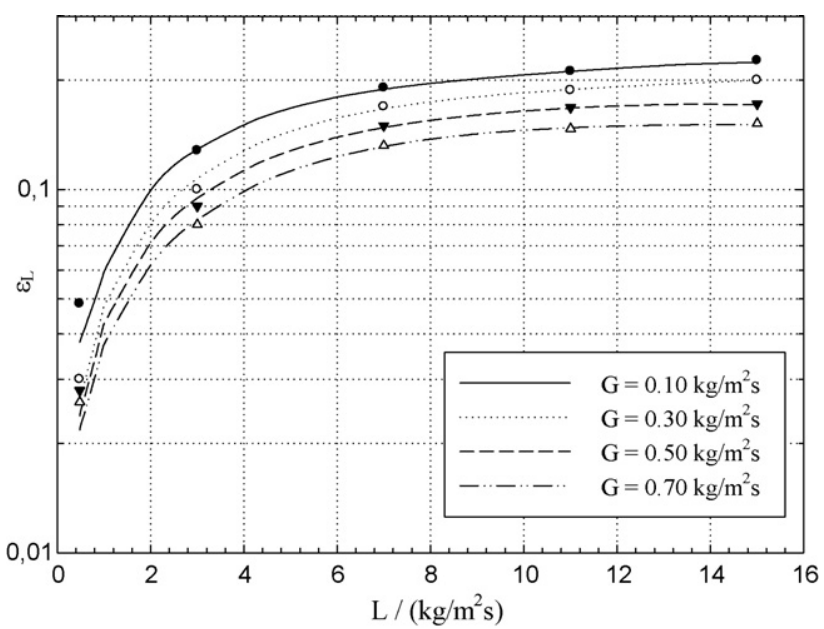

Fig. 10. Effect of gas flow rate on liquid holdup vs. liquid flow rate ( $P=30$ bar, $d=2 \mathrm{~mm}$; experimental data from Nemec and Levec [22]). 

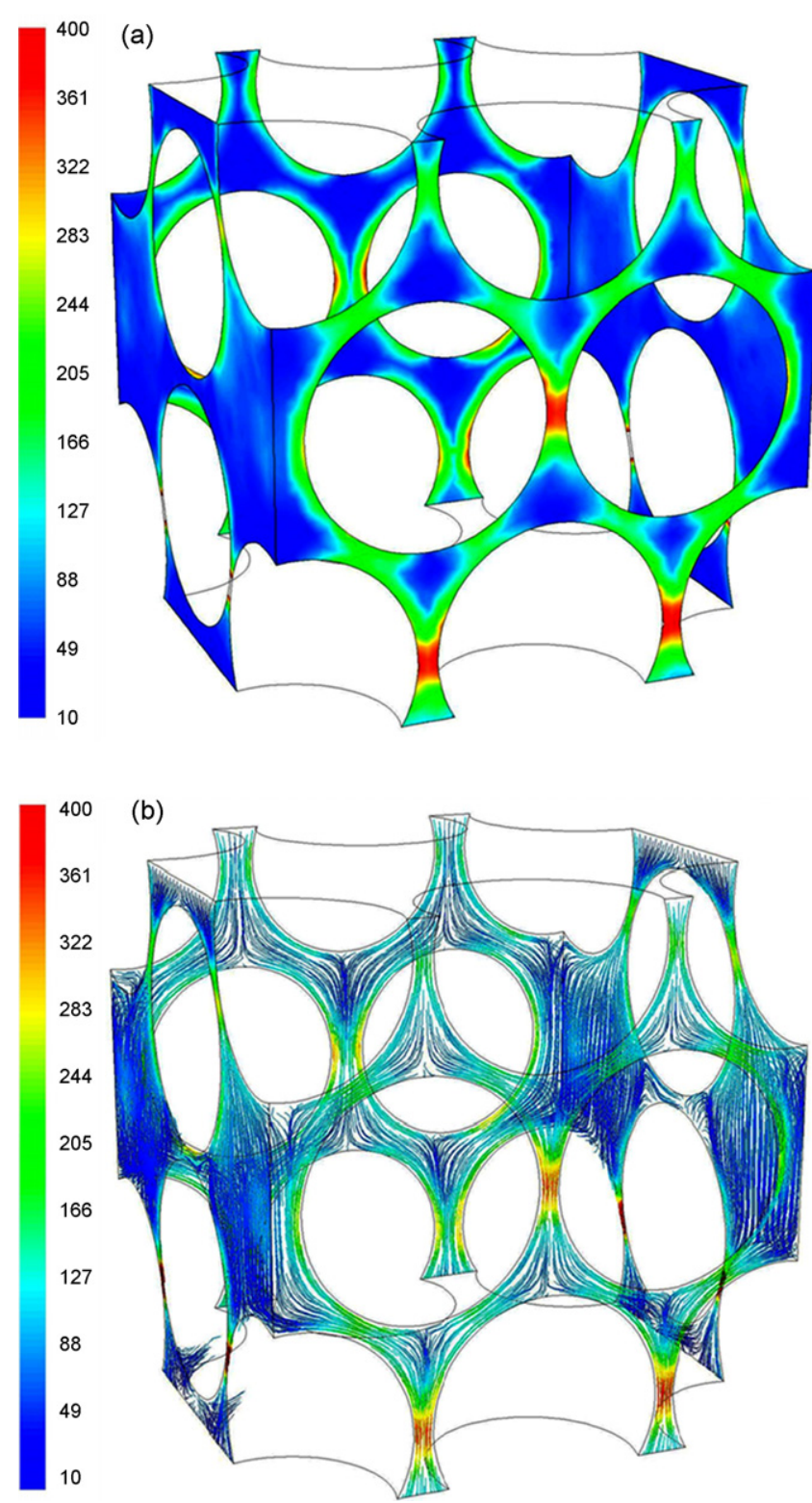

Fig. 11. (a) Vertical colour maps of Reynolds number in laminar flow; (b) streamlines coloured by Reynolds number $\left(P=30 \mathrm{bar}, L=5 \mathrm{~kg} /\left(\mathrm{m}^{2} \mathrm{~s}\right), G=0.7 \mathrm{~kg} /\left(\mathrm{m}^{2} \mathrm{~s}\right), d=2 \mathrm{~mm}\right)$.

flow encountered at low-gas and -liquid flow rates, the Eulerian model was employed in laminar flow simulations $(R e<400)$. In Fig. 11(a), it is represented a snapshot of Reynolds number in a colour map for four vertical planes corresponding to the bulk space between the catalyst particles. The deviations of the local velocity near the solid surfaces observed in Fig. 11(a) indicate the existence of more or less stagnant zones near the points of approximation between spheres. In fact, for packed beds, large deviations of this nature might result in a variation of the boundary layer thickness values over the sphere surface. Indeed, according to Fig. 11(b) in where it was also mapped the streamlines for the same planes coloured by the Reynolds number for the gas phase, the condition that the flow should be well developed in order for the standard wall model to be valid, might be fully met in the case of a trickle flow operation. Therefore, the good agreement achieved for the calculations performed with $10^{6}$ of tetrahedral cells validated both the computed pressure drop and the liquid holdup.

\section{Conclusions}

A unique physic-based three-dimensional model has been proposed to model trickle-bed reactors at elevated pressures for predicting the hydrodynamic parameters pressure drop and liquid holdup. The CFD unified approach allowed the rigorous fluid transport equations to be solved locally, to better understand the phenomena including fundamental point force balance and takes into account the interphase coupling terms in the momentum transfer between the gas, liquid and solid phases. The CFD calculations with different mesh sizes were checked against experiments and a good agreement was achieved.

The mesh generation technique and grid convergence were evaluated to establish grid independence using a relative error measure of hydrodynamic parameters magnitude between the coarse and fine solutions. Successive refinements of each mesh style have been considered to better resolve regions of significant velocity gradients encountered in the multiphase system. The coarse mesh affected considerably the accuracy of simulations so that an optimum number of cells was achieved with a fine mesh and used throughout the simulation activities.

The effect of packing size on the pressure drop and liquid holdup is ascribed by different specific surface area of the packing material for the trickle-bed reactor. It has been found that the packing characteristics affect the gas and liquid velocity with the effect of gas velocity being prominent at high-superficial gas mass velocities. The theoretical predictions from the model correctly account for the strong influence of the gas flow on the hydrodynamic behaviour of the trickle-bed reactors, as shown by the several results examined in this work. The important influence of the gas flow is attributed to the interactions phenomena exerted by the gas phase on the liquid phase. These interactions clearly appear to be significant at high-superficial gas mass velocities.

Finally, the Reynolds numbers evaluation in flow colour maps was related to the nature of standard wall functions used in the CFD model. The deviations of the local velocity near the solid surfaces were observed which indicated the existence of more or less stagnant zones near the points of approximation retained from the packing spheres which enables the unsteady state behaviour exhibited by TBR in tricking flow conditions.

\section{Acknowledgments}

The authors gratefully acknowledged the financial support of REMOVALS - 6th Framework Program for Research and Technological Development - FP06 project no. 018525 and Fundação para a Ciência e Tecnologia, Portugal.

\section{References}

[1] M.P. Dudukovic, F. Larachi, P.L. Mills, Multiphase catalytic reactors: a perspective on current knowledge and future trends, Catal. Rev.-Sci. Eng. 44 (1) (2002) $123-246$.

[2] S.K. Bhargava, J. Tardio, J. Prasad, K. Foger, D.B. Akolekar, S.C. Grocott, Wet oxidation and catalytic wet oxidation, Ind. Eng. Chem. Res. 45 (4) (2006) 1221-1258

[3] A.E. Sáez, R.G. Carbonell, Hydrodynamic parameters for gas liquid cocurrent flow in packed beds, AIChE J. 31 (1) (1985) 52-62.

[4] S. Goto, J.M. Smith, Trickle bed reactors performance. I. Hold-up and mass transfer effects, AIChE J. 21 (1975) 706-713.

[5] R.A. Holub, M.P. Dudukovic, P.A. Ramachandran, Pressure drop, liquid hold-up and flow regime transition in trickle flow, AIChE J. 39 (2) (1993) 302-321.

[6] M.H. Al-Dahhan, F. Larachi, M.P. Dudukovic, A. Laurent, High pressure tricklebed reactors: a review, Ind. Eng. Chem. Res. 36 (8) (1997) 3292-3314.

[7] R.G. Carbonell, Multiphase flow models in packed beds, Oil Gas Sci. Technol.Revue de l'IFP 55 (2000) 417-425.

[8] A. Gianetto, V. Specchia, Trickle-bed reactors: state of the art and perspectives, Chem. Eng. Sci. 47 (1992) 3197-3213.

[9] A. Lakota, J. Levec, R.G. Carbonell, Hydrodynamics of trickling flow in packed beds: relative permeability concept, AIChE J. 48 (2002) 731-738. 
[10] L.A. Tarca, B.P.A. Grandjean, F. Larachi, Embedding monotonicity and concavity in the training of neural networks by means of genetic algorithms: application to multiphase flow, Comp. Chem. Eng. 28 (2004) 1701-1713.

[11] S.T. Sie, R. Krishna, Process development and scale up. III. Scale-up and scale-down of trickle bed processes, Rev. Chem. Eng. 14 (1998) 203-252.

[12] Y. Jiang, M.R. Khadilkar, M.H. Al-Dahhan, M.P. Dudukovic, CFD modeling of multiphase in packed bed reactors: results and applications, AIChE J. 48 (2002) 716-730.

[13] R. Farmer, R. Pike, G. Cheng, CFD analyses of complex flows, Comp. Chem. Eng. 29 (2005) 2386-2403.

[14] P.R. Gunjal, V.V. Ranade, R.V. Chaudhari, Computational study of a single-phase flow in packed beds of spheres, AIChE J. 51 (2) (2005) 365-378.

[15] R.J.G. Lopes, A.M.T. Silva, R.M. Quinta-Ferreira, Kinetic modelling and tricklebed CFD studies in the catalytic wet oxidation of vanillic acid, Ind. Eng. Chem. Res. 46 (25) (2007) 8380-8387.

[16] R.J.G. Lopes, R.M. Quinta-Ferreira, Trickle-bed CFD studies in the catalytic wet oxidation of phenolic acids, Chem. Eng. Sci. 62 (24) (2007) 7045-7052.
[17] A.J. Sederman, L.F. Gladden, Transition to pulsing flow in trickle-bed reactors studied using MRI, AIChE J. 51 (2005) 615-621.

[18] GAMBIT 2, User's Manual to GAMBIT 2, Fluent Inc., Centrera Resource Park, 10 Cavendish Court, Lebanon, USA, 2005.

[19] M. Nijemeisland, A.G. Dixon, Comparison of CFD simulations to experiment for convective heat transfer in a gas-solid fixed bed, Chem. Eng. J. $82(1-3)(2001)$ 231-246.

[20] FLUENT 6.1, User's Manual to FLUENT 6.1, Fluent Inc., Centrera Resource Park, 10 Cavendish Court, Lebanon, USA, 2005.

[21] A. Attou, G.A. Ferschneider, Two-fluid model for flow regime transition in gas-liquid trickle-bed reactors, Chem. Eng. Sci. 54 (21) (1999) 5031-5037.

[22] D. Nemec, J. Levec, Flow through packed bed reactors. 2. Two phase concurrent downflow, Chem. Eng. Sci. 60 (24) (2005) 6958-6970.

[23] W. van der Merwe, W. Nicol, Characterization of multiple flow morphologies within trickle flow regime, Ind. Eng. Chem. Res. 44 (25) (2005) 9446-9450.

[24] W.J.A. Wammes, K.R. Westerterp, The influence of reactor pressure on the hydrodynamics in a cocurrent gas-liquid trickle-bed reactor, Chem. Eng. Sci. 45 (8) (1990) 2247-2254. 